\title{
A Cytotoxic Lipopeptide from the Sponge-Derived Fungus Aspergillus versicolor
}

\author{
Yoon Mi Lee, ${ }^{a}$ Hung The Dang, ${ }^{a}$ Jongki Hong, ${ }^{\dagger}$ Chong-O. Lee, ${ }^{\star}$ Kyung Sook Bae, ${ }^{\S}$ Dong-Kyoo Kim, ${ }^{\#}$ and Jee H. Jung* \\ College of Pharmacy, Pusan National University, Busan 609-735, Korea. E-mail: jhjung@pusan.ac.kr \\ ${ }^{\dagger}$ College of Pharmacy, Kyung Hee University, Seoul 130-701, Korea \\ ${ }^{\ddagger}$ Korea Research Institute of Chemical Technology, Daejon 305-343, Korea \\ ${ }^{\S}$ Korea Research Institute of Bioscience and Biotechnology, Daejon 305-333, Korea \\ ${ }^{\#}$ Biohealth Product Research Center, Inje University, Kimhae 621-749, Korea \\ Received September 24, 2009, Accepted November 13, 2009
}

Key Words: Aspergillus versicolor, Lipopeptide, Cytotoxicity

Sponge-derived fungi are a prolific source of bioactive secondary metabolites. To date, more than 134 metabolites from over 34 sponge-derived fungal strains have been reported. Although the nature of the associations between sponges and fungi is not completely understood, sponge-associated fungi are an interesting source of new bioactive natural products. ${ }^{1,2}$

In our previous study on cytotoxic compounds from the sponge-derived fungus Aspergillus versicolor, three polyketides were isolated. ${ }^{3}$ In a subsequent study, a new peptide (1) was isolated by bioactivity-guided fractionation. Peptides are well-established bioactive metabolites from marine sources. Approximately 20 peptides have been reported from sponge-derived fungi, including efrapeptins E $\alpha, \mathrm{H}, \mathrm{RHM} 3$, RHM4 (from two fungi, Acremonium sp. and Metarrhizium sp), ${ }^{4}$ homodestcardin (from Fusarium graminearum), ${ }^{5}$ clonostachysins A and B (from Clonostachys rogersoniana), ${ }^{6}$ a cyclodepsipeptide (from a Clonostachys sp), ${ }^{7}$ linear octapeptides (from an Acremonium sp), ${ }^{8}$ petrosifungins A and B (from Penicillium brevicompactum), ${ }^{9}$ fellutamides A and B (from Penicillium fellutanum), ${ }^{10}$ and halovirs (from a Scytalidium $\mathrm{sp}$ ). ${ }^{11}$ This paper describes the isolation, structure elucidation, and cytotoxicity evaluation of a new lipopeptide from the fungus Aspergillus versicolor.

The fungal strain was isolated from a marine sponge Petrosia sp., and identified as Aspergillus versicolor by morphological analysis. The fungal culture was extracted with EtOAc at room temperature. The EtOAc extract showed significant toxicity to brine shrimp larvae ( $\mathrm{LC}_{50} 32 \mu \mathrm{g} / \mathrm{mL}$ ). This EtOAc extract was partitioned between $n$-hexane and $90 \%$ aqueous $\mathrm{MeOH}$. The latter layer, which was toxic to brine shrimp larvae $\left(\mathrm{LC}_{50} 0.4\right.$ $\mu \mathrm{g} / \mathrm{mL}$ ), was subjected to reversed-phase MPLC to afford 13 fractions. Fraction $7\left(\mathrm{LC}_{50}<0.1 \mu \mathrm{g} / \mathrm{mL}\right)$, one of the bioactive fractions, was further subjected to reversed-phase HPLC to yield compound 1, which was named fellutamide C. Fellutamide C (1) is structurally similar to fellutamides $\mathrm{A}(2)$ and $\mathrm{B}(3)$, which were first isolated from the fish-derived fungus Penicillium fellutanum. ${ }^{10}$ If only the functional group of the terminal unit is considered, fellutamide $\mathrm{C}(\mathbf{1})$ is a reduced alcohol form of fellutamide $B$ (3).

Fellutamide C (1) was isolated as a light violet, amorphous powder. Its molecular formula was defined as $\mathrm{C}_{27} \mathrm{H}_{51} \mathrm{~N}_{5} \mathrm{O}_{7}$ on the basis of HRFABMS and NMR data. The exact mass of the [M+

${ }^{\mathrm{a}}$ These authors equally contributed to this work.
$\mathrm{Na}]^{+}$ion $(\mathrm{m} / \mathrm{z}$ 580.3694) matched well with the expected formula $(\Delta+0.8 \mathrm{mmu})$. General analyses of the ${ }^{1} \mathrm{H}$ and ${ }^{13} \mathrm{C} \mathrm{NMR}$ spectra of compound 1 revealed characteristic peptide resonances, including five amide carbon signals at $\delta 176.8,173.3,173.0$, 172.3, and 172.0. Four proton signals for two amino groups $\left(\mathrm{NH}_{2}\right)$ were observed as two pairs of broad singlets $(\delta 7.44 /$ 6.95 and $\delta 7.22 / 6.75)$. In the ${ }^{1} \mathrm{H}$ NMR spectrum using DMSO- $d_{6}$ as the solvent, three $\mathrm{NH}$ protons of peptide bonds were observed as doublets $(\delta 8.15,8.02$, and 7.43$)$. This proved to be a convenient starting point for identifying the individual amino acid unit by COSY, HSQC, and HMBC experiments (Figure 1). Further analysis of the NMR data of compound 1 revealed the presence of an amino alcohol unit (Lol, leucine-derived leucinol), common amino acid units (asparagine and glutamine), and a fatty acyl chain (3-hydroxydodecanoic acid). The presence of a leucinol (Lol) moiety was apparent from the COSY correlation of the hydroxymethylene protons at $\delta 3.46\left(\mathrm{H}-\beta^{\prime}\right)$, with the $N$ methine proton signal at $\delta 3.94(\mathrm{H}-\alpha)$. The presence of a gluta-
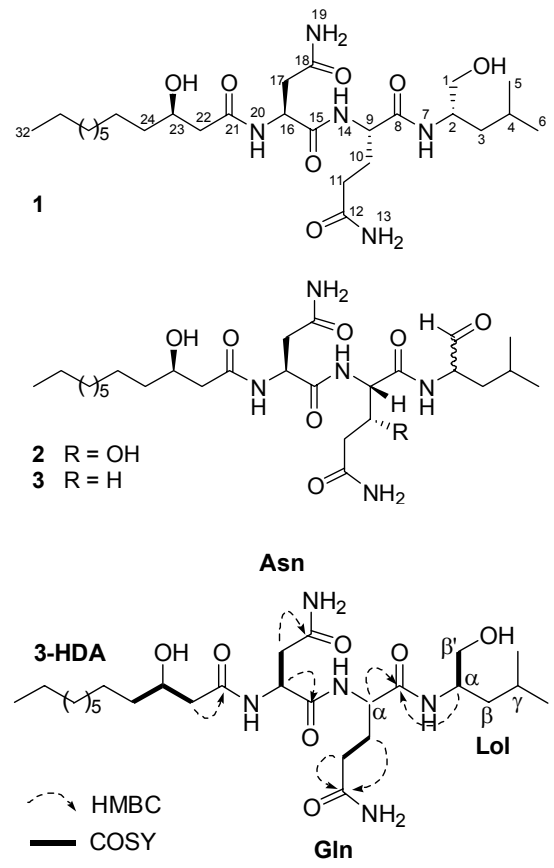

Figure 1. Key COSY and HMBC correlations of compound 1. 


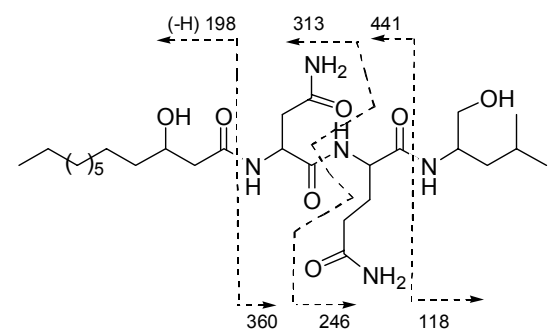

Figure 2. Key FAB-CID-MS/MS fragmentations of the $[\mathrm{M}+\mathrm{H}]^{+}$ion of compound 1.

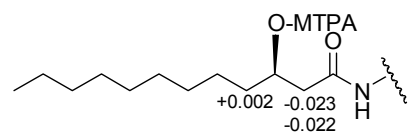

Figure 3. $\Delta \delta\left(\Delta_{S}-\Delta_{R}\right)$ values for the MTPA esters of compound $\mathbf{1}$.

mine (Gln) moiety was suggested by the COSY correlations of the $\alpha, \beta$, and $\gamma$ protons in an isolated $\mathrm{C}_{3} \mathrm{H}_{5}$ unit, which was expanded to an aminodicarboxyl unit on the basis of the HMBC correlations of the $\alpha$ proton to a carbonyl carbon $(\delta 172.0)$ and the $\gamma$ proton to another carbonyl carbon $(\delta 176.8)$. The connectivity of the Lol and Gln moieties was confirmed by the HMBC correlation of the $\alpha$-proton of the Lol unit with the carbonyl carbon $(\delta 172.0)$ of the Gln residue. The asparagine (Asn) unit was suggested by the HMBC correlations of the $\alpha$-methine proton at $\delta 4.63$ with the carbonyl carbon signal at $\delta 172.3$, and the $\beta$ methylene protons at $\delta 2.80 / 2.72$ with another amide carbonyl carbon signal at $\delta 173.0$. Finally, the presence of a fatty acyl moiety 3-hydroxydodecanoic acid (3-HDA) at the $\mathrm{N}$-terminal of the peptide was confirmed by NMR and MS. In the HMBC spectrum, there were correlations between the two methylene proton signals $(\mathrm{H}-22)$ at $\delta 2.43$ and 2.32 and the carbonyl carbon signal at $\delta 173.3$ (C-21). The FAB-CID-MS/MS spectrum of compound 1 corroborated the planar structure assigned by NMR spectroscopy. Fragmentations of the $[\mathrm{M}+\mathrm{H}]^{+}$ion $(\mathrm{m} / \mathrm{z} 558)$ at the peptide (amide) bonds were expected as fragment ion pairs at $m / z$ 441/118 (3-HDA-Asn-Gln/Lol), 313/246 (3-HDA-Asn/ Gln-Lol), and 199/360 (3-HDA/Asn-Gln-Lol) (Figure 2). Except the fragment ion pair of 3-HDA/Asn-Gln-Lol, other fragmentations were observed as expected. The fragment on pair of 3-HDA/Asn-Gln-Lol was observed at $m / z$ 198/360. The fragment of $m / z 199$ had apparently undergone the further loss of a proton.

The absolute configuration of the three amino acids of compound 1 were determined using Marfey's method. ${ }^{12}$ Three pairs of amino acid standards, including D-/L-aspartic acid, D-/Lglutamic acid, and D-/L-leucine were derivatized with Marfey's reagent's (FDAA) to establish the reference $\mathrm{R}_{\mathrm{f}}$ values of the corresponding amino acid-FDAA derivatives. The amino acidFDAA derivatives were characterized by reversed-phase TLC (D-Asp-FDAA derivative: $\mathrm{R}_{\mathrm{f}} 0.76$; L-Asp-FDAA derivative: $\mathrm{R}_{\mathrm{f}} 0.84$; D-Glu-FDAA derivative: $\mathrm{R}_{\mathrm{f}} 0.67$; L-Glu-FDAA derivative: $R_{f} 0.73$; $D$-Leu-FDAA derivative: $R_{f} 0.08$; L-Leu-FDAA derivative: $\mathrm{R}_{\mathrm{f}} 0.23$ ). As fellutamide $\mathrm{C}(\mathbf{1})$ contained a leucinol
Table 1. ${ }^{1} \mathrm{H}$ and ${ }^{13} \mathrm{C}$ NMR Data of Compound 1

\begin{tabular}{|c|c|c|c|c|}
\hline unit & position & $\delta_{\mathrm{C}}{ }^{b}$ & $\delta_{\mathrm{H}}(J \text { in } \mathrm{Hz})^{a}$ & HMBC \\
\hline \multirow[t]{8}{*}{ Lol } & $\mathrm{NH}^{c}$ & & $8.02, \mathrm{~d}(7.0)$ & \\
\hline & $\alpha$ & $48.8, \mathrm{~d}$ & $3.94, \mathrm{~m}$ & $\beta, \gamma, \mathrm{CO}$ \\
\hline & $\beta$ & $38.6, \mathrm{t}$ & $1.42, \mathrm{~m}$ & $\alpha, \gamma, \delta, \mathrm{Me}$ \\
\hline & & & $1.33, \mathrm{~m}$ & \\
\hline & $\beta^{\prime}$ & $64.0, \mathrm{t}$ & $3.46, \mathrm{~d}(5.0)$ & $\alpha, \beta, \mathrm{CO}$ \\
\hline & $\gamma$ & $25.3, d$ & $1.62, \mathrm{~m}$ & \\
\hline & $\mathrm{CH}_{3}$ & $22.0, \mathrm{q}$ & $0.89, \mathrm{~d}(6.8)$ & $\beta, \gamma$ \\
\hline & & $23.5, \mathrm{q}$ & $0.92, \mathrm{~d}(6.8)$ & \\
\hline \multirow[t]{9}{*}{ Gln } & $\mathrm{NH}^{c}$ & & $7.43, \mathrm{~d}(7.0)$ & \\
\hline & $\mathrm{CO}$ & $172.0, \mathrm{~s}$ & & \\
\hline & $\alpha$ & $52.9, \mathrm{~d}$ & $4.27, \mathrm{dd}(15.5,7.0)$ & $\gamma, \mathrm{CO}$ \\
\hline & $\beta$ & $27.9, \mathrm{t}$ & $2.15, \mathrm{~m}$ & $\alpha, \gamma, \mathrm{CO}$ \\
\hline & & & $1.90, \mathrm{~m}$ & \\
\hline & $\gamma$ & $31.5, \mathrm{t}$ & $2.30, \mathrm{~m}$ & $\alpha, \beta, \underline{\mathrm{CONH}}_{2}$ \\
\hline & $\underline{\mathrm{CONH}_{2}}$ & $176.8, \mathrm{~s}$ & & \\
\hline & $\mathrm{CONH}_{2}{ }^{c}$ & & 7.22 , br s & \\
\hline & & & 6.75, br s & \\
\hline \multirow[t]{8}{*}{ Asn } & $\mathrm{NH}^{c}$ & & $8.15, \mathrm{~d}(7.0)$ & \\
\hline & $\mathrm{CO}$ & $172.3, \mathrm{~s}$ & & \\
\hline & $\alpha$ & $50.2, \mathrm{~d}$ & $4.63, \mathrm{t}(7.0)$ & $\beta, \mathrm{CO}$ \\
\hline & $\beta$ & $36.2, \mathrm{t}$ & $2.80, \mathrm{dd}(15.5,7.0)$ & $\alpha, \mathrm{CONH}_{2}$ \\
\hline & & & $2.72, \mathrm{dd}(15.5,7.0)$ & \\
\hline & $\mathrm{CONH}_{2}$ & $173.0, \mathrm{~s}$ & & \\
\hline & $\mathrm{CONH}_{2}{ }^{c}$ & & 7.44 , br s & \\
\hline & & & 6.95, br s & \\
\hline \multirow[t]{11}{*}{ 3-HDA } & 21 & 173.3, s & & \\
\hline & 22 & $43.6, \mathrm{t}$ & $2.43, \mathrm{dd}(15.5,4.5)$ & $1,3,4$ \\
\hline & & & $2.32, \mathrm{~d}(15.5)$ & \\
\hline & 23 & $67.5, \mathrm{~d}$ & $3.97, \mathrm{~m}$ & 2,4 \\
\hline & 24 & $37.1, \mathrm{t}$ & $1.48, \mathrm{~m}$ & $3, \mathrm{CH}_{2}$ \\
\hline & $25-30$ & $31.4(2 \mathrm{C}), \mathrm{t}$ & $1.29-1.36$ & $4, \mathrm{CH}_{2}$ \\
\hline & & $29.2, \mathrm{t}$ & & \\
\hline & & $29.0, \mathrm{t}$ & & \\
\hline & & $28.9(2 \mathrm{C}), \mathrm{t}$ & & \\
\hline & 31 & $22.3, \mathrm{t}$ & & \\
\hline & 32 & $14.1, \mathrm{q}$ & $0.88, \mathrm{t}(7.0)$ & \\
\hline
\end{tabular}

${ }^{a}$ Measured in $\mathrm{CD}_{3} \mathrm{OD}(500 \mathrm{MHz}),{ }^{b}$ Measured in $\mathrm{CD}_{3} \mathrm{OD}(100 \mathrm{MHz}),{ }^{c}$ Measured in DMSO- $d_{6}(500 \mathrm{MHz}) .{ }^{d} \mathrm{HMBC}$ correlations are from proton stated to the indicated carbon(s).

moiety, it was first oxidized to convert the leucinol to a leucine moiety before hydrolysis. ${ }^{10}$ After oxidation of compound $\mathbf{1}$ using the Jones reagent, followed by acid hydrolysis and derivatization with Marfey's reagent, the resulting mixture clearly showed three spots on the TLC with $\mathrm{R}_{\mathrm{f}}$ values of $0.84,0.73$, and 0.23 , which showed a good match to the corresponding LAsp-FDAA, L-Glu-FDAA, and L-Leu-FDAA derivatives, respectively.

The absolute configuration of the 3-hydroxy group in the acyl moiety of compound $\mathbf{1}$ was defined by the modified Mosher's method. ${ }^{13}$ A positive $\Delta \delta\left(\delta_{S}-\delta_{R}\right)$ value was observed for $\mathrm{H}-24$ 
Table 2. Cytotoxicity Data of Compound $\mathbf{1}^{a}$

\begin{tabular}{cccccc}
\hline compound & A549 & SK-OV-3 & SK-MEL-2 & XF498 & HCT15 \\
\hline $\mathbf{1}$ & 33.1 & 23.8 & 5.1 & 3.9 & 3.1 \\
doxorubicin & 0.02 & 0.11 & 0.07 & 0.22 & 0.33 \\
\hline
\end{tabular}

${ }^{a}$ Data expressed in $\mathrm{ED}_{50}$ values $(\mu \mathrm{M})$. A549, human lung cancer; SK-OV3, human ovarian cancer; SK-MEL-2, human skin cancer; XF498, human CNS cancer; HCT15, human colon cancer.

$(+0.002)$, while a negative value was observed for $\mathrm{H}-22$ $(-0.023)$, indicating that the configuration of the hydroxy group is $R$ (Figure 3 ). Therefore, the absolute configuration of compound 1 was established as $(2 S, 9 S, 16 S, 23 R)$.

Since the structure of fellutamide $\mathrm{C}$ is closely related to fellutamides A (2) and B (3), it might be supposed that this fungus also produces $\mathbf{2}$ and $\mathbf{3}$. However, we could not detect or isolate these analogues except an additional unknown fellutamide $\mathrm{C}$ analogue from the broth.

Fellutamide C (1) was evaluated for its cytotoxicity against a panel of five human solid tumor cell lines (Table 2). The compound showed cytotoxiciy to most of the five human solid tumor cell lines. The skin cancer (SK-MEL-2), CNS cancer (XF498), and colon cancer (HCT15) cells were more sensitive to this peptide. Fellutamides A and B were reported to be potent cytotoxins with $\mathrm{IC}_{50}$ values ranging from 0.1 to $0.8 \mu \mathrm{g} / \mathrm{mL}$ against murine leukemia P388 and L1210, and human epidermoid carcinoma $\mathrm{KB}$ cells. ${ }^{10}$ However, the activity of these analogues cannot be directly compared because different cell lines were employed for fellutamides A and B and a positive control was not included in the test.

\section{Experimental}

General Procedure. The optical rotations were measured using a JASCO P-1020 digital polarimeter. The ${ }^{1} \mathrm{H}$ and ${ }^{13} \mathrm{CNMR}$ spectra were recorded on Varian Inova $500 \mathrm{MHz}$ and Varian Unity $400 \mathrm{MHz}$ spectrometers, respectively. The chemical shifts are reported with reference to the respective residual solvent or deuterated solvent peaks $\left(\delta_{\mathrm{H}} 3.30\right.$ and $\delta_{\mathrm{C}} 49.0$ for $\mathrm{CD}_{3} \mathrm{OD}$, $\delta_{\mathrm{H}} 2.50$ and $\delta_{\mathrm{C}} 39.5$ for DMSO). The FABMS data was obtained on a JEOL JMS SX-102A spectrometer. The HRFABMS data was obtained on a JEOL JMS SX-101A spectrometer. HPLC was performed on a C8-5E Shodex packed column (preparative, $250 \times 10 \mathrm{~mm}, 5 \mu \mathrm{m}, 100 \AA$ ) , and Shodex C18E (preparative, $250 \times 10 \mathrm{~mm}, 5 \mu \mathrm{m}, 100 \AA$ ) columns using a Shodex RI detector.

Animal Material. The sponge was collected by hand using SCUBA (20 m in depth) in 2004 off the coast of Jeju Island, Korea. The collected sample was frozen immediately. This specimen was identified as Petrosia sp. and the morphology of the sponge specimen was described elsewhere. ${ }^{14}$

Fungal Strain. The fungal strain was isolated from the marine sponge Petrosia sp. After rinsing in sterile sea water, small pieces of the surface and inner tissue of the sponge were homogenized and inoculated on malt extract agar (MEA) petri dishes. The sterilized MEA medium (prepared with $75 \%$ sea water, obtained locally) contained glucose $(20 \mathrm{~g} / \mathrm{L})$, malt extract $(20 \mathrm{~g} / \mathrm{L})$, $\operatorname{agar}(20 \mathrm{~g} / \mathrm{L})$, peptone $(1 \mathrm{~g} / \mathrm{L})$, and antibiotics $(10,000$ units $/ \mathrm{mL}$ penicillin and $10 \mathrm{mg} / \mathrm{mL}$ streptomycin, $5 \mathrm{~mL} / \mathrm{L})$. The emerging fungal colonies were transferred to the same media in a petri dish and incubated at $25^{\circ} \mathrm{C}$ for 10 - 14 days to allow colony development. ${ }^{15}$ The pure fungal strain, which is designated as PF10M, was identified as Aspergillus versicolor by morphological analysis. The strain was deposited at KRIBB, Korea.

Extraction and Isolation. Fermentation was performed in 250 $\mathrm{mL}$ malt media in $500 \mathrm{~mL}$ Erlenmeyer flasks for subculturing. For a large scale culture, $250 \mathrm{~mL}$ of the subculture was transferred to a $2 \mathrm{~L}$ Erlenmeyer flask each containing $20 \mathrm{~g} / \mathrm{L}$ malt media, and fermentation was carried out on a rotary shaker (32 ${ }^{\circ} \mathrm{C}, 150 \mathrm{rpm}, 21$ days). The cultured fungus $(8 \mathrm{~L})$ was extracted with $16 \mathrm{~L}$ of EtOAc, to afford the EtOAc extract $(2.0 \mathrm{~g}$, brine shrimp lethality, $\mathrm{LC}_{50} 32 \mu \mathrm{g} / \mathrm{mL}$ ), which was partitioned between $n$-hexane $\left(0.7 \mathrm{~g}, \mathrm{LC}_{50} 51 \mu \mathrm{g} / \mathrm{mL}\right)$ and $90 \%$ aq $\mathrm{MeOH}(1.27$ $\left.\mathrm{g}, \mathrm{LC}_{50} 0.4 \mu \mathrm{g} / \mathrm{mL}\right)$. The $90 \% \mathrm{MeOH}$ layer was subjected to a step-gradient MPLC (ODS-A, $120 \AA$, S-30/50 mesh) eluting with $50 \%$ to $100 \% \mathrm{MeOH}$ to afford 13 fractions. Fraction 7 , which is one of the bioactive fractions $\left(\mathrm{LC}_{50}<0.1 \mu \mathrm{g} / \mathrm{mL}\right.$ ), was subjected to reversed-phase HPLC (C8 Shodex Pack ODS, $250 \times 10 \mathrm{~mm}, 5 \mu \mathrm{m}, 100 \AA$ ) eluting with $75 \%$ aq $\mathrm{MeOH}$ to afford 5 subfractions. Compound 1 ( $4.8 \mathrm{mg})$ was obtained by the purification of subfractions 3 and 4, by reversed-phase HPLC (C8 Shodex Pack ODS, $250 \times 10$ mm, $5 \mu \mathrm{m}, 120 \AA$ ).

Fellutamide C(1). Light violet, amorphous powder; $[\alpha]_{D}-128$ (c $0.18, \mathrm{MeOH}) ; \mathrm{IR}\left(\mathrm{CHCl}_{3}\right) v_{\max } 3500,1650,1550 \mathrm{~cm}^{-1} ;{ }^{1} \mathrm{H}$ and ${ }^{13} \mathrm{C}$ NMR, see Table 1; LRFABMS $m / z 580[\mathrm{M}+\mathrm{Na}]^{+}, m / z 558$ $[\mathrm{M}+\mathrm{H}]^{+}$; HRFABMS $m / z 580.3694[\mathrm{M}+\mathrm{Na}]^{+}$(calcd for $\mathrm{C}_{27} \mathrm{H}_{51^{-}}$ $\mathrm{N}_{5} \mathrm{O}_{7} \mathrm{Na}, 580.3686$ ); FAB-CID-MS/MS $m / z$ 441/118 (3-HDAAsn-Gln/Lol), 313 /246 (3-HDA-Asn/Gln-Lol), and 198 /360 (3-HDA/Asn-Gln-Lol).

Evaluation of Cytotoxicity. The cytotoxicity assays against five human tumor cell lines (A549, human lung cancer; SK-OV3 , human ovarian cancer; SK-MEL-2, human skin cancer; XF 498, human CNS cancer; and HCT15, human colon cancer) were performed at the Korea Research Institute of Chemical Technology. The rapidly growing cells were harvested, counted, and inoculated into 96-well microtiter plates at the appropriate concentrations $\left(1-2 \times 10^{4}\right.$ cells/well). After incubation for $24 \mathrm{~h}$, the compounds dissolved in culture medium (RPMI 1640, Gibco; $10 \%$ FBS, Gibco) were applied to the culture wells in triplicate followed by incubation for $48 \mathrm{~h}$ at $37{ }^{\circ} \mathrm{C}$ in a $5 \% \mathrm{CO}_{2}$ atmosphere. The culture was fixed with cold TCA and stained with $0.4 \%$ SRB (sulforhodamine B, Sigma) dissolved in $1 \%$ acetic acid. After dissolving the bound dye with $10 \mathrm{mM}$ unbuffered tris base using a gyrotatory shaker, the absorbance at $520 \mathrm{~nm}$ was measured using a microplate reader (Dynatech Model MR 700). The $50 \%$ inhibitory concentration $\left(\mathrm{ED}_{50}\right)$ was defined as the concentration that reduced the absorbance by $50 \%$ compared to the control level in the untreated wells.

Preparation of the $(R)$ - and $(S)$-MTPA Esters of 1. Two portions (each $0.5 \mathrm{mg}$ ) of compound 1 were treated overnight with $(S)-(+)$ - and $(R)-(-)-\alpha$-methoxy- $\alpha$-(trifluoromethyl)phenylacetyl chloride $(0.6 \mu \mathrm{L})$ in $\mathrm{C}_{5} \mathrm{D}_{5} \mathrm{~N}(0.5 \mathrm{~mL})$ at room temperature to afford the $(R)$ - and $(S)$-MTPA esters, respectively (1rand 1s, respectively). $^{13}$

(S)-MTPA Ester of 1 (1s): ${ }^{1} \mathrm{H}$ NMR (pyridine- $d_{5}, 500 \mathrm{MHz}$ ) 4.302 (1H, m, H-23), $\delta 2.184$ (1H, m, H-22b), 2.109 (1H, m, H-22a), 1.552 (2H, m, H-24). 
(R)-MTPA Ester of 1(1r): ${ }^{1} \mathrm{H}$ NMR (pyridine- $d_{5}, 500 \mathrm{MHz}$ ) 4.274 (1H, m, H-23), $\delta 2.207$ (1H, m, H-22b), 2.131 (1H, m, H-22a), 1.550 (2H, m, H-24).

Oxidation, Hydrolysis, and Derivatization of 1. Compound 1 $(0.8 \mathrm{mg})$ was dissolved in acetone and the solutions were cooled to $0{ }^{\circ} \mathrm{C}$. Two microliter of Jones reagent $\left(6.68 \mathrm{~g}\right.$ of $\mathrm{CrO}_{3}$ in 5.75 $\mathrm{mL}$ of concentrated $\mathrm{H}_{2} \mathrm{SO}_{4}$, then $\mathrm{H}_{2} \mathrm{O}$ until volume of $25 \mathrm{~mL}$ ) was added, and the mixture was stirred at $0{ }^{\circ} \mathrm{C}$ for $2 \mathrm{~h}$. The reaction mixture was then filtered and washed with diethyl ether. The filtrate was concentrated under reduced pressure to afford a residue, which was then dissolved in $1.0 \mathrm{~mL}$ of $6 \mathrm{~N} \mathrm{HCl}$ and hydrolyzed for $24 \mathrm{~h}$ at $110{ }^{\circ} \mathrm{C}$. The reaction mixture was cooled to room temperature and evaporated with $\mathrm{MeOH}$ several times to remove the excess $\mathrm{HCl}$. The mixture obtained was dissolved in $100 \mu \mathrm{L}$ of acetone and $50 \mu \mathrm{L}$ of $\mathrm{H}_{2} \mathrm{O}$. The solution was treated with $40 \mu \mathrm{L}$ of $1 \mathrm{M} \mathrm{NaHCO}_{3}$ followed by $100 \mu \mathrm{L}$ of $1 \%$ FDAA (1-fluoro-2,4-dinitrophenyl-5-L-alanine amide) in acetone. The reaction mixture was heated to $40{ }^{\circ} \mathrm{C}$ for $2 \mathrm{~h}$ and then cooled to room temperature. The reaction was quenched by adding $20 \mu \mathrm{L}$ of $2 \mathrm{~N} \mathrm{HCl}$ and the sample was ready for TLC analysis.

Derivatization of Standard Amino Acids with Marfey's Reagent (FDAA) and TLC Analysis. ${ }^{12,16,17}$ Two hundred microliters of a $1 \%$ FDAA acetone solution was added to a $2.0 \mathrm{~mL}$ reaction vial containing $5 \mu \mathrm{M}$ of the pure amino acid standard in 100 $\mu \mathrm{L}$ of $\mathrm{H}_{2} \mathrm{O}$. Subsequently, $40 \mu \mathrm{L}$ of $1.0 \mathrm{M} \mathrm{NaHCO}_{3}$ was added. The mixture was maintained at $40{ }^{\circ} \mathrm{C}$ for $1 \mathrm{~h}$ in a Reacti-Therm heating module. After cooling the mixture to RT, $20 \mu \mathrm{L}$ of $2 \mathrm{~N}$ $\mathrm{HCl}$ was added to quench the reaction, and the resulting solution was diluted with the mobile phase to make the chromatographic sample solution for TLC analysis (RP- $18 \mathrm{~F}_{254 \mathrm{~s}}, 50 \% \mathrm{MeOH}$ in water).

Acknowledgments. The authors wish to thank Prof. C. J. Sim of Hannam University for identifying the sponge. H. T. Dang acknowledges the Postdoctoral fellowship from Pusan National University. This study was supported by a grant from the Marine Biotechnology Program funded by Ministry of Land, Transport, and Maritime Affairs, Korea.

\section{References}

1. Höller, U.; Wright, A. D.; Matthee, G. F.; König, G. M.; Draeger, S.; Aust, H. J.; Schulz, B. Mycol. Res. 2000, 104, 1354.

2. Renner, M. K.; Jensen, P. R.; Fenical, W. J. Org. Chem. 2000, 65, 4843.

3. Lee, Y. M.; Mansoor, T. A.; Hong, J.; Lee, C. O.; Bae, K. S.; Jung, J. H. Nat. Prod. Sci. 2007, 13, 90 .

4. Boot, C, M.; Amagata, T.; Tenney, K.; Compton, J. E.; Pietraszkiewicz, H.; Valeriote, F. A.; Crews P. Tetrahedron 2007, 63, 9903.

5. Amagata, T.; Morinaka, B. I.; Amagata, A.; Tenney, K.; Valeriote, F. A.; Lobkovsky, E.; Clardy, J.; Crews, P. J. Nat. Prod. 2006, 69, 1560.

6. Adachi, K.; Kaneo, K.; Puntip, W.; Miyuki, N.; Yoshikazu, S. J. Antibiot. 2005, 58, 145.

7. Cruz, L. J.; Insua, M. M.; Baz, J. P.; Trujillo, M.; Rodriguez-Mias, R. A.; Oliveria, E.; Giralt, E.; Albericio, F.; Cañedo, L. M. J. Org. Chem. 2006, 71, 3335 .

8. Boot, C. M.; Tenney, K.; Valeriote, F. A.; Crews, P. J. Nat. Prod. 2006, 69, 83

9. Bringmann, G.; Lang, G.; Steffens, S.; Schaumann, K. J. Nat. Prod. 2004, 67, 311 .

10. Shigemori, H.; Wakuri, S.; Yazawa, K.; Nakamura, T.; Sasaki, T.; Kobayashi, J. Tetrahedron 1991, 47, 8529.

11. Rowley, D. C.; Kelly, S.; Jensen, P.; Fenical, W. Bioorg. Med. Chem. 2004, 12, 4929.

12. Marfey, P. Carlsberg Res. Commun. 1984, 49, 591.

13. Dale, J. A.; Mosher, H. S. J. Am. Chem. Soc. 1973, 95, 512.

14. Lim, Y. J.; Park, H. S.; Im, K. S.; Lee, C. O.; Hong, J.; Lee, M. Y.; Kim, D. K.; Jung, J. H. J. Nat. Prod. 2001, 64, 46.

15. Hyde, K. D.; Farrant, C. A.; Jones, E. B. G. Bot. Mar. 1987, 30, 291.

16. Williams, D. E.; Craig, M.; Holmes, C. F. B.; Andersen, R. J. J. Nat. Prod. 1996, 59, 570.

17. Maddox, N. J.; Lin, S. J. Liq. Chrom. Rel. Technol. 1999, 22, 1367. 